times mathematics might also be included in this programme."

Although agreeing with the decision that bright pupils may not take their School Certificates before they are sixteen, Mr. Butler believes that the education authorities will move, or may be led to move, towards the decision whereby people should take their real examination of quality when they are seventeen. Before that age there would have to be examinations, but they should be of the "test of attainment" type based partly upon internal record. Standards, however, cannot be maintained through the examination system. Standards can be restored only by re-establishing the one vital link in education, and that is the relationship between teacher and taught. This will be achieved by a restoration of liberty of interpretation to the schools of Britain and their masters.

T. H. HawkINS

\section{JUAN DE LA CIERVA FOUNDA- TION FOR TECHNICAL RESEARCH, SPAIN}

$\mathrm{A}^{\mathrm{N}}$ $\mathrm{N}$ illustrated brochure describing the origin, aims and organisation of the Juan de la Cierva Foundation for Technical Research* which under the Higher Council for Sciontific Research, created by the law of November 24, 1939, is responsible for all scientific work in Spain of a technical and industrial character, gives a fairly comprehensive picture of the organisation in Spain of scientific and industrial research. The Technical Advisory Council, which is the chief technical advisory organ of the governing body, is assisted by various technical committees which advise on the planning and development of any specific research activity.

Research work is carried out in a number of dependent institutes which investigate technical problems in a specific branch of applied science. These institutes include the Leonardo Torres Queredo Institute for Scientific Apparatus, the Institute for Technical Research on Building and Cement, the National Institute for Fuel Research, the Institute for Research on Fats, Oils and Related Products, the National Institute for Rationalization, the Welding Institute, the Iron and Steel Institute and the Institute of Electronics. The Foundation has also established a Department of Industrial Ferment. ation in the Institute of Microbiology, the Plastics Section of the Alonso Barba Chemical Institute, and the Section of Marine Biology in the Institute of Applied Biology, Barcelona. Research is also conducted by agreement with the Foundation in a number of independent institutions, such as the Institute for Technical Research, Barcelona, the Spanish Electro-Technical Association, the LaffonSelgas Laboratory for Electrical-Acoustical Research, the Institute for Experimental Research in Forestry the National Institute for Technical Aeronautics and the Cabro Sotelo Research Centre for Synthetic Fuels and Lubricating Oils.

Other institutions like the Alonso de Santa Cruz Institute of Physics, the Institute of Entomology, the Antonio de G. Rocasolano Institute of Physical Chemistry, the Daza de Valdés Optical Institute and

- Juan de la Cierva Foundation for Technical Research: its Organization and Development. Pp. 40. (Madrid : Juan de la Cierva the Institute for Soil Research, as well as the Universities of Madrid, Barcelona, Seville, Granada, Orviedo, and Valencia, are collaborating with the Foundation, while close liaison is fostered between the research centres of the Foundation and industry. The Foundation also seeks to encourage the training of research workers as well as the interchange of workers and of publications with foreign technical institutions. Brief notes on the work carried out by the institutes and research centres of the Foundation are included.

\section{THE UNIT OF HEAT}

TN 1948 the International Unions of Chemistry and of Physics, and the International Conference of Weights and Measures, agreed to adopt the joule as the unit of heat in place of the calorie ${ }^{1}$. A memorandum on this subject was recently prepared by Sir Charles Darwin, chairman of the Symbols Committee of the Royal Society. After careful consideration of this memorandum, the Council of the Royal Society recommended that, in future, in the Society's publications, all quantities of heat and related concepts such as specific heat, entropy, etc., should be expressed both in joules and in calories. To facilitate this, the Society has issued a pamphlet in which the text of Sir Charles's memorandum and the Council's recommendations, tables of conversion factors from various calories and British thermal units to joules, together with examples of their use in textual, tabular and diagrammatic matter, are printed. No indication is given, however, as to how these factors have been determined; but it is presumed that they are in accordance with the best available experimental data.

It is made clear in the memorandum that, in accordance with the statement of the First Law of Thermodynamics that heat is energy, the joule, of $10^{7}$ ergs, is the basic unit. This alone would not necessitate its use in actual practice; but it is well known that the several calories which are used are all different in value and that calorimetric work of high precision is invariably done electrically, involving electrical units which give results directly in joules to a high order of accuracy. Although the joule is theoretically the correct unit, it must be admitted that in the past nearly all work has been expressed in calories, and, doubtless, heat quantities expressed solely in joules may be unfamiliar to many men of science. For this reason, and in order to give prominence to the joule, it is recommended in the pamphlet that both the joule value and, in paren. theses, the equivalent value in calories be quoted. This is similar to the practice recently advocated of giving metric equivalents to British mechanical units when the latter are used. It is strange, however, to find that the textual example shown in the pamphlet uses the reverse order to that recommended, the heat of combustion of carbon monoxide in oxygen being given in k.cal. per mole and the equivalent joule value in parentheses.

The replacement of the calorie by the joule is intended only for strictly scientific work, and the hope is expressed that, by the publication by the Royal Society of this pamphlet, the practice advocated by the Council of the Royal Society will be recommended and followed by other scientific bodies.

1 Nature, 163, 427 and 164, 262 (1949). 